\title{
Detection of the Presence of Bordetella pertussis by Real-Time Polymerase Chain Reaction in Children Diagnosed with Pertussis and among their Household Contacts
}

Zehra Diyar Tamburacı Uslu' ${ }^{*}$, Mehmet Ceyhan², Ener Cagri Dinleyici ${ }^{3}$, Zafer Kurugol ${ }^{4}$, Bedriye Nuray Alpman', Eda Karadag Oncel ${ }^{2}$, Venhar Gurbuz ${ }^{2}$, Emre Aycan ${ }^{2}$, Hasan Tezer ${ }^{5}$ and Belgin Gulhan ${ }^{6}$

${ }^{1}$ Clinic of Pediatrics, Cankiri State Hospital, Cankiri, Turkey

${ }^{2}$ Department of Pediatrics, Unit of Infectious Diseases, Hacettepe University School of Medicine, Ankara, Turkey

${ }^{3}$ Department of Pediatrics, Osmangazi University School of Medicine, Eskisehir, Turkey

${ }^{4}$ Department of Pediatrics, Ege University School of Medicine, Izmir, Turkey

${ }^{5}$ Department of Pediatrics, Unit of Infectious Diseases, Gazi University School of Medicine, Ankara, Turkey

${ }^{6}$ Clinic of Pediatrics, Diskapi Training and Research Hospital, Ankara, Turkey

\begin{abstract}
Background: Despite high vaccination coverage, pertussis continues to be a great public health problem. Adults and adolescents are source of infection for infants who are too young to be completely vaccinated. The aim of the study is detect if there is a household transmission of pertussis.

Methods: Presence of Bordetella pertussis among the household contacts of the children who had had the positive result for Bordetella pertussis by real-time polymerase chain reaction was detected.

Results: Of the 173 infants with clinical suspicion of pertussis, $48(27.7 \%)$ turned out to be positive by PCR. The mothers of 19 (41.3\% of all tested mothers) of them were also PCR positive for $B$. pertussis, being the family member most frequently infected.

Conclusion: Despite high coverage of pertussis vaccination in Turkey, pertussis is prevalent both in incompletely protected infants and older children. High rate of presence of the bacteria in the household contacts depicts the importance of further pertussis booster vaccination in adolescents, adults and the targeted vaccination of the adults having close contacts with infants (cocoon strategy).
\end{abstract}

Keywords: Infant; Pertussis; Polymerase chain reaction; Household contacts; Cocoon

\section{Introduction}

Despite high vaccination coverage, pertussis continues to be a great public health problem. Although recent (in 2009) vaccination coverage for 3 doses of DTP (DTP3) is as high as $96 \%$ in Turkey, it was low in the past years (e.g.: it was $68 \%$ in 2003) [1]. Due to low vaccination coverage rates in the past years and waning immunity [2], in addition to lack of further booster doses beyond childhood disease incidence in adults and adolescents resurges. In contrary to infants, in whom complications and deaths because of pertussis are frequent, severity of the disease in these age groups is low. However adults and adolescents are source of infection for infants who are too young to be completely vaccinated [3]. Aim of this study is the detection of household transmission of pertussis.

\section{Materials and Methods}

We performed a hospital based, multi-center, prospective study. Children aged $0-5$ years those had the diagnosis of pertussis according to World Health Organization's pertussis case definition [4] from four university hospitals and two state hospitals in Turkey were included in the study between 06.02.2012 and 22.10.2012. Nasopharyngeal (NP) swabs were taken from the children and their household contacts at the same visit. Close contacts those did not accompany to the children were asked to provide NP swab samples within following 5 days. All the contacts were either asymptomatic or having symptoms before the index case at the time of sample collection. Presence of Bordetella pertussis (B. pertussis) was searched in children with real- time PCR using IS481 primer. NP swabs taken from household contacts, of the positive index cases were then tested.
All laboratory tests were performed at microbiology laboratory of Hacettepe University Hospital, Pediatric Infectious Diseases Unit.

\section{DNA isolation}

DNA was isolated from nasopharyngeal swab by using QIAamp DNA mini kit. $20 \mu$ l QIAGEN protease or proteinase $\mathrm{K}$ and then 200 $\mu \mathrm{L}$ Buffer $\mathrm{AL}$ were added to samples. The samples were mixed by vortex for 15 seconds. These mixtures were incubated at $56^{\circ} \mathrm{C}$ for 10 minutes. Samples were centrifuged briefly in $1.5 \mathrm{ml}$ micro-centrifuge tube to remove drops from the inside of the lid. Ethanol (96-100\%) of $200 \mu \mathrm{l}$ was added to the samples and was mixed again by vortex for 15 seconds. After mixing, the sample were centrifuged again briefly in the $1.5 \mathrm{ml}$ microcentrifuge tube to remove drops from the inside of the lid. Finally, samples were centrifuged at $8000 \mathrm{rpm}$ for 1 minute, and then added $500 \mu \mathrm{l}$ Buffer AW1 and centrifuged again at $8000 \mathrm{rpm}$ for $1 \mathrm{~min}$; added $500 \mu \mathrm{L}$ Buffer AW2 and centrifuged at full speed 14,000 rpm for 3 minutes and then added $200 \mu$ l Buffer AE $8000 \mathrm{rpm}$ for 1 minute (Qiagen, Hilden, Germany).

*Corresponding author: Zehra Diyar Tamburaci Uslu, Dumlupınar Bulvarı , Akdeniz Universitesi Hastanesi 07059, Kampus, Antalya, Turkey, Tel: 00905057664383 Fax: 009024222743 20; E-mail: tamburacizehra@gmail.com

Received April 17, 2013; Accepted August 12, 2013; Published August 17, 2013 Citation: Tamburacı Uslu ZD, Ceyhan M, Dinleyici EC, Kurugol Z, Alpman BN, et al. (2013) Detection of the Presence of Bordetella pertussis by Real-Time Polymerase Chain Reaction in Children Diagnosed with Pertussis and among their Household Contacts. J Vaccines Vaccin 4: 199. doi: 10.4172/2157-7560.1000199 Copyright: (c) 2013 Tamburacı Uslu ZD, et al. This is an open-access article distributed under the terms of the Creative Commons Attribution License, which permits unrestricted use, distribution, and reproduction in any medium, provided the original author and source are credited. 
Citation: Tamburacı Uslu ZD, Ceyhan M, Dinleyici EC, Kurugol Z, Alpman BN, et al. (2013) Detection of the Presence of Bordetella pertussis by Real-Time Polymerase Chain Reaction in Children Diagnosed with Pertussis and among their Household Contacts. J Vaccines Vaccin 4: 199. doi: $10.4172 / 2157-7560.1000199$

Page 2 of 3

\section{Real-time}

PCR Primer and probe sequences were used for amplification of the Pertactin (prn 13) gene segment of B.pertussis. The reaction volume of the PCR was $20 \mu \mathrm{l}$ containing $10 \mu \mathrm{l} 2 \times$ PrecisionTM MasterMix (Qiagen, Hilden, Germany), $1 \mu$ l bpert Primer/Probe mix, $4 \mu$ RNAse/ DNAse free water, and finally $5 \mu$ extracted DNA. Clinical samples were run as duplicates, and cycling conditions were $10 \mathrm{~min}$ at $95^{\circ} \mathrm{C}$ followed by 50 cycles of $10 \mathrm{~s}$ at $95^{\circ} \mathrm{C}$ and $1 \mathrm{~min}$ at $60^{\circ} \mathrm{C}$. PCR amplification and data analysis were performed using a Rotor-Gene Q (Qiagen, Hilden, Germany) [5,6]. Samples were regarded as positive for B. pertussis when both reactions and the majority of reactions (should the sample was reanalyzed), exceeded the fixed threshold of 0.015 normalized fluorescence units and showed an amplification curve [6].

This study was approved by Ethics Committee of Hacettepe University and Turkish Ministry of Health. Informed consent was obtained from all parents and/ or legal guardians before enrollment.

Chi-square test was performed for statistical analysis. $\mathrm{P}<0.05$ was considered statistically significant.

\section{Results}

Of total 173 cases, $48(27.7 \%)$ was found to have B. pertussis. Positivity rates were $25 \%$ and $39.4 \%$ at below and above 1 -year-ofage, respectively (Table 1). Of 107 family members tested, $42(39.3 \%)$ were infected. Percentage of mothers, fathers, and siblings infected among children with pertussis are $41.3 \%$ (19/46), 32\% (8/25) and $40 \%$ $(8 / 20)$, respectively. These rates for the mothers, fathers and siblings of the children with pertussis below 1 year of age were $42.8 \%(15 / 35)$, $22.2 \%(4 / 18)$, and $33.3 \%(5 / 15)$, respectively. Percentage of the infected mothers among the other infected contacts was higher in the cases below one year of age comparing the cases above one year of age $(50 \%$ vs. $33.3 \%)$. However this difference was not statistically significant $(\mathrm{p}=0,327)$. Proportion of the infected mothers of the cases below and above one year of age were $15 / 35$ and $4 / 11$, respectively ( $\mathrm{p}=0.703$ ).

Fathers, siblings, and the other family members accounted for $19 \%$, $19 \%$, and $16.7 \%$ of all positive household contacts, respectively.

\section{Discussion}

Of the recruited patients in the study, $27.7 \%$ turned out to be positive. This rate was consistent with findings of the other studies (17-23.5\%) performed for the detection of pertussis in the children having prolonged cough in Turkey [7-9]. The incidence of pertussis reported to the Ministry of Health of Turkey is 0.1 per 100.000 persons or below since 2005 (0.01-0.10/100.000 between 2005 and 2010). Population of the four cities where the study sites located was roughly 10.000 .000 in 2012 [10]. Total number of infected persons in current study is 90 . Therefore incidence of pertussis can be calculated as $0.9 / 100.000$ persons. This incidence rate is at least 9 times more than the reported numbers. Albeit, there is underreporting due to difficulties in diagnosing pertussis and atypical presentation of the patients in addition to other factors [11]. On the other hand there are other health care facilities in these cities, and all patients with pertussis may not seek medical attention. Therefore one can expect the incidence of pertussis to be much higher than afore-mentioned values. Parent positivity in our study was $64.2 \%$. Our rate is a little bit higher that the results of studies performed in other countries (20-55\%) [3].This is primarily because of high positivity of the mothers in our study. This is an expected result. Because seroprevalence studies performed in Turkey showed high rate of infection $[12,13]$. For example, according to a field study performed in Turkey by Kurtoglu et al., prevalence of pertussis infection is between 7.4 and $15.4 \%$ in three selected provinces [12]. Additionally, antipertussis toxin antibody positivity is higher in adult females than adult males despite the lack of adult and preschool vaccination during study period [1]. Percentage of the mother positivity was higher in the index cases below one year of age. It may be due to the fact that pertussis is transmitted via air droplets and mothers are the closest contacts of the infants at that age. Higher B. pertussis bacterial load in the infants' secretions may also be another explanation [14]. However, we did not measure B. pertussis DNA in NP swabs. Additionally, in 2010 a second booster for the school age children ( $1^{\text {st }}$ grade) was started in Turkey [1]. This may also be of some effect. Findings set out in this study showed need for booster doses beyond school entry. In addition to universal immunization of adolescent and adults, targeted vaccination of the adults having close contact with infants (cocoon strategy) should be considered. The Advisory Committee on Immunization Practices (ACIP) and UK Department of Health currently recommends vaccination during late pregnancy $[15,16]$. However, in Turkey, it can be discussed after more clinical and safety data is available.

To our knowledge this is the first study in Turkey showing household transmission of pertussis.

There are two limitations of the study. First limitation is the number of cases which is limited for broad generalizations. The cause is the epidemiological nature of the disease and time limitations. We will be able to give the results with higher number of cases with ongoing study. Second limitation is related with the difficulties in the clinical diagnosis of pertussis. Although we used reliable and acceptable clinical parameters in the study, pertussis can be seen in an unusual clinical form in a population routinely vaccination.

\section{Conclusion}

Despite high coverage of pertussis vaccination in Turkey [1], pertussis is prevalent both in incompletely protected infants and older children. High rate of presence of the bacteria in the household contacts depicts the importance of further pertussis booster vaccination in adolescents, adults and the targeted vaccination of the adults having close contacts with infants (cocoon strategy).

\begin{tabular}{|c|c|c|c|c|c|c|c|c|c|c|c|c|}
\hline & \multirow[b]{2}{*}{$\begin{array}{c}\text { Negative } \\
\text { cases }\end{array}$} & \multirow[b]{2}{*}{$\begin{array}{c}\text { Positive } \\
\text { cases }\end{array}$} & \multirow[b]{2}{*}{$\begin{array}{l}\text { Families } \\
\text { of positive } \\
\text { cases }\end{array}$} & \multicolumn{9}{|c|}{ Number of positive household contacts* } \\
\hline & & & & $\begin{array}{l}\text { Mother } \\
(\mathrm{n} / \mathrm{N})\end{array}$ & $\begin{array}{l}\text { Father } \\
(\mathrm{n} / \mathrm{N})\end{array}$ & $\begin{array}{l}\text { Sibling } \\
(n / N)\end{array}$ & $\begin{array}{c}\text { Father's } \\
\text { sister }(n / N)\end{array}$ & $\begin{array}{l}\text { Uncle's } \\
\text { wife }(n / N)\end{array}$ & Uncle $(n / N)$ & $\begin{array}{c}\text { Grand- } \\
\text { father }(n / N)\end{array}$ & $\begin{array}{l}\text { Grand- } \\
\text { mother } \\
(\mathrm{n} / \mathrm{N})\end{array}$ & Total $(\mathbf{n} / \mathbf{N})$ \\
\hline$<1$-year-of age & 105 & 35 & 22 & $15 / 35$ & $4 / 18$ & $5 / 15$ & $1 / 2$ & $1 / 1$ & $1 / 1$ & $2 / 5$ & $1 / 5$ & $30 / 82$ \\
\hline$\geq 1$-year-of age & 20 & 13 & 7 & $4 / 11$ & $4 / 7$ & $3 / 5$ & $1 / 1$ & - & - & - & $0 / 1$ & $12 / 25$ \\
\hline TOTAL & 125 & 48 & 29 & $19 / 46$ & $8 / 25$ & $8 / 20$ & $2 / 3$ & $1 / 1$ & $1 / 1$ & $2 / 5$ & $1 / 6$ & $42 / 107$ \\
\hline
\end{tabular}

* Distribution of the family members: of 22 families of the positive cases aged $<1$ year: mother only 9 , mother and father 3 , uncle's wife 1 , sibling 3 , mother and grandfather 1 , grandfather 1 , father and grandmother 1 , uncle and uncle's wife 1, mother and sibling 2; and of 7 families of the positive cases aged $\geq 1$ year: mother only 2 , mother and father 1 , father and father's sister 1, father and sibling 2 , mother and sibling 1. n: number of contacts infected, N: number of contacts tested.

Table 1: Distribution of the positive cases and their household contacts according to age groups. 
Citation: Tamburacı Uslu ZD, Ceyhan M, Dinleyici EC, Kurugol Z, Alpman BN, et al. (2013) Detection of the Presence of Bordetella pertussis by Real-Time Polymerase Chain Reaction in Children Diagnosed with Pertussis and among their Household Contacts. J Vaccines Vaccin 4: 199. doi: $10.4172 / 2157-7560.1000199$

\section{References}

1. Buzgan T (2011) History of Vaccination Policies, in Turkey. Pediatr Inf 5: 235-238.

2. Wendelboe AM, Van Rie A, Salmaso S, Englund JA (2005) Duration of immunity against pertussis after natural infection or vaccination. Pediatr Infect Dis J 24: S58-61.

3. Wendelboe AM, Njamkepo E, Bourillon A, Floret DD, Gaudelus J, et al. (2007) Transmission of Bordetella pertussis to young infants. Pediatr Infect Dis J 26: 293-299.

4. WHO-recommended surveillance standard of pertussis.

5. Vincart B, De Mendonça R, Rottiers S, Vermeulen F, Struelens MJ, et al. (2007) A specific real-time PCR assay for the detection of Bordetella pertussis. J Med Microbiol 56: 918-920.

6. Litt DJ, Jauneikaite E, Tchipeva D, Harrison TG, Fry NK (2012) Direct molecular typing of Bordetella pertussis from clinical specimens submitted for diagnostic quantitative (real-time) PCR. J Med Microbiol 61: 1662-1668.

7. Aksakal FN, Cöplü N, Ceyhan MN, Sönmez C, Ozkan S, et al. (2007) High incidence of Pertussis among schoolchildren with prolonged cough in Turkey. Tohoku J Exp Med 211: 353-358.

8. Yildirim I, Ceyhan M, Kalayci O, Cengiz AB, Secmeer G, et al. (2008) Frequency of pertussis in children with prolonged cough. Scand J Infect Dis 40:314-319.

9. Gürsel D, Aslan A, Sönmez C, Koturoğlu G, Cöplü N, et al. (2012) Detection of
Bordetella pertussis infection by culture, real-time polymerase chain reaction and serologic tests among children with prolonged cough]. Mikrobiyol Bul 46 : 211-224.

10. Turkish Statistical Institute. Population of provinces by years.

11. Gari AY D, Strebel PM, Bardenheier B, Brennan M, Tachdjian R, et al. (1999) Changing epidemiology of pertussis in the United States: increasing reported incidence among adolescents and adults, 1990-1996. Clin Infect Dis 28: 12301237.

12. Kurtoğlu D, Gözalan A, Cöplü N, Miyamura K, Ishida S, et al. (2008) Pertussis seroprevalence and vaccination status in three selected provinces of Turkey] Mikrobiyol Bul 42: 389-398.

13. Vatansever U, Cöplü N, Oner N, Sönmez C, Karasalihoglu S, et al. (2005) Seroprevalance of Bordetella pertussis antibodies among healthy adolescent girls in Edirne. Swiss Med Wkly 135: 531-536.

14. Nakamura Y, Kamachi K, Toyoizumi-Ajisaka H, Otsuka N, Saito R, et al. (2011) Marked difference between adults and children in Bordetella pertussis DNA load in nasopharyngeal swabs. Clin Microbiol Infect 17:365-370.

15. Centers for Disease Control and Prevention. (2013) Updated recommendation for use of tetanus toxoid, reduced diphtheria toxoid, and acellular pertussis vaccine (Tdap) in pregnant women-Advisory Committee on Immunization Practices (ACIP), 2012. MMWR Morbid Mortal Wkly Rep 62:131-135.

16. Department of Health (2012) Pertussis (whooping cough) vaccination programme for pregnant women introduced on 1 October 2012. 